\title{
PLANTAS MEDICINAIS UTILIZADAS NO NORDESTE DO BRASIL: UMA REVISÃO DE LITERATURA
}

\author{
PLANTAS MEDICINALES UTILIZADAS EN EL NORESTE DE BRASIL: UNA \\ REVISIÓN DE LA LITERATURA
}

\section{MEDICINAL PLANTS USED IN NORTHEASTERN BRAZIL: A LITERATURE REVIEW}

\author{
Zion Nascimento de Souza'; Bárbara Rafaela da Silva Barros²; Kaline Soares da Silva ${ }^{3}$; Ricardo Sérgio da \\ Silva ${ }^{4}$; Cristiane Moutinho Lagos de Melo ${ }^{5}$.
}

DOI: https://doi.org/10.31692/978-65-991061-9-4.115-132

\begin{abstract}
RESUMO
A região Nordeste do Brasil possui uma extensão de aproximadamente $1.558 .000 \mathrm{~km}^{2}$ de território, destacando-se a sua vasta diversidade de espécies vegetais, climas e hábitats. A diversidade florística dessa região, tem proporcionado uma grande variedade de plantas que são utilizadas por diversos grupos, como: ribeirinhos, pescadores, agricultores, indígenas e comunidades rurais, para o tratamento e prevenção de diversas doenças. Esse conhecimento da medicina popular, tem chamado a atenção de diversos pesquisadores em todo o mundo, a fim de testarem a eficácia e a veracidade por trás dos benefícios aparentemente verídicos, no tratamento dessas doenças. Dessa forma, o presente estudo tem como objetivo a análise e discussão a respeito das plantas medicinais mais utilizadas no Nordeste brasileiro. E para isso, foi realizada uma análise qualitativa, quanto a importância e uso de tais plantas, na região Nordeste do Brasil. Através da análise de 104 artigos das plataformas Scielo, Pubmed e Google Acadêmico, datados entre 2009 e 2019. Como resultado, foram identificadas 20 espécies de plantas pertencentes a 17 famílias e as informações a respeito do seu uso medicinal foram relatadas em todas as regiões. Também é importante destacar a grande importância e potencial de aplicação das plantas medicinais do Nordeste do Brasil para o tratamento de enfermidades com seu uso popular e sua utilização para a produção de fármacos, aliado às futuras investigações biológicas voltadas aos benefícios e ao controle de segurança necessário para os devidos usos.
\end{abstract}

Palavras-Chave: Etnofarmacologia; plantas medicinais; potencial terapêutico; região nordeste.

\section{RESUMEN}

La región Nordeste de Brasil tiene una extensión aproximada de 1,558,000km² de territorio, destacando su gran diversidad de especies vegetales, climas y hábitats. La diversidad florística de esta región ha proporcionado una amplia variedad de plantas que son utilizadas por diferentes grupos, tales como: ribereños, pescadores, agricultores, indígenas y comunidades rurales, para el tratamiento y prevención de diversas enfermedades. Este conocimiento de la medicina popular ha llamado la atención de varios investigadores alrededor del mundo, con el fin de probar la efectividad y veracidad detrás de los aparentemente verdaderos beneficios, en el tratamiento de estas enfermedades. Así, el presente estudio tiene como objetivo analizar y discutir las plantas medicinales más utilizadas en el noreste de Brasil. Y para eso, se realizó un

\footnotetext{
${ }^{1}$ Bacharelado em Biomedicina, UFPE, zionnascimento@ hotmail.com

${ }^{2}$ Mestranda em Ciências Biológicas, UFPE, barbarabarrosbio@ gmail.com

${ }^{3}$ Bacharelado em Agronomia, INACAP/ IFPE, kalis.soares8@gmail.com

${ }^{4}$ Mestre em Morfotecnologia, UFPE, profricardosergio.bio@gmail.com

${ }^{5}$ Doutora em Ciências Biológicas, UFPE, cristianemout@gmail.com
} 
análisis cualitativo, sobre la importancia y uso de tales plantas, en la región Nordeste de Brasil. Mediante el análisis de 104 artículos de las plataformas Scielo, Pubmed y Google Acadêmico, fechados entre 2009 y 2019. Como resultado, se identificaron 20 especies de plantas pertenecientes a 17 familias y se reportó información sobre su uso medicinal en todas las regiones. También es importante resaltar la gran importancia y potencial de la aplicación de plantas medicinales en el noreste de Brasil para el tratamiento de enfermedades con su uso popular y su uso en la producción de medicamentos, combinado con futuras investigaciones biológicas dirigidas a los beneficios y el control de seguridad necesario. para usos adecuados.

Palabras clave: Etnofarmacología; plantas medicinales; potencial terapéutico; región nordeste.

\section{ABSTRACT}

The Northeast region of Brazil has an extension of approximately 1,558,000 $\mathrm{km}^{2}$ of territory, highlighting its vast diversity of plant species, climates and habitats. The floristic diversity of this region has provided a wide variety of plants that are used by several groups, such as: Riverside, fishermen, farmers, indigenous people and rural communities, for the treatment and prevention of various diseases. This knowledge of popular medicine has called the attention of several researchers around the world, in order to test the efficacy and truthfulness behind the seemingly true benefits in the treatment of these diseases. This way, the present study aims to analyze and discuss the most used medicinal plants in northeastern Brazil. In order to do this, a qualitative analysis was performed regarding the importance and use of such plants in the northeast region of Brazil. Through the analysis of 104 articles of the platforms Scielo, Pubmed and Scholar Google, dated between 2009 and 2019. As a result, 20 species of plants belonging to 17 families were identified and information about their medicinal use was reported in all regions. It is also important to highlight the great importance and potential application of medicinal plants in northeastern Brazil for the treatment of diseases with their popular use and their use for the production of drugs, allied to future biological investigations to the benefits and safety control required for proper uses.

Keywords: Ethnopharmacology; medicinal plants; northeast region; therapeutic potential.

\section{Introdução}

O Brasil é o país mais rico do mundo em biodiversidade terrestre, pois abriga cerca de 20\% das espécies animais, vegetais e de microrganismos do planeta (Nogueira et al., 2010).

A região Nordeste do país é marcada por um intenso uso etnofarmacológico de diferentes plantas por populações de comunidades locais. Esse conhecimento tradicional é passado através das gerações e observa-se que existe um amplo conhecimento sobre métodos alternativos usados para curar ou aliviar sintomas de algumas doenças (Baptistel et al. 2014). A interação entre conhecimento tradicional e indústria farmacêutica originou a fitoterapia, entendida como o tratamento com plantas medicinais ou com seus derivados farmacológicos (Firmo et al., 2011).

Segundo a Organização Mundial da Saúde (OMS), planta medicinal é considerada todo e qualquer vegetal que possui, em um ou mais órgãos, substâncias que podem ser utilizadas para fins terapêuticos ou que sejam precursores de fármacos semissintéticos. O emprego de plantas medicinais para a manutenção e a recuperação da saúde tem ocorrido ao longo dos 
tempos utilizando-se formas simples de administração, como chás, decocções, infusões e macerados. A possibilidade de desvendar a estrutura e o funcionamento dessas moléculas bioativas desperta o interesse de diversas áreas da pesquisa (Lana et al., 2010).

De fato, no Brasil, estima-se que $25 \%$ do faturamento da indústria farmacêutica são originados de medicamentos derivados de plantas (Brasil, 2016).

Os seres humanos têm usado as plantas para fins medicinais devido ao vasto rol de compostos químicos sintetizados pelas mesmas (Petrovska, 2012), dentre eles, estão os metabólitos secundários, estes compostos são geralmente sintetizados pelas plantas de acordo com as suas necessidades específicas, que incluem as condições ambientais, as interações com outras plantas e a proteção contra predadores (Savithramma et al., 2011). No entanto, na vida humana, estes compostos podem ser utilizados como medicamentos (princípios ativos ou excipientes), aromatizantes ou corantes. Esses metabólitos possuem atividades biológicas marcantes e, diferentemente dos metabólitos primários, apresentam-se em baixas concentrações. Embora muitos dados científicos afirmem que os metabolitos secundários não desempenham um papel crucial para o crescimento, desenvolvimento e reprodução das células vivas, eles são fundamentais na defesa e proteção da planta contra qualquer dano ecológico (Samuni-Blank et al., 2012). De uma maneira geral os principais metabólitos encontrados e estudados são os compostos fenólicos (ácidos fenólicos, taninos e flavonoides), alcalóides, terpenóides e compostos nitrogenados (Ferreira,2012).

Baseado nas propriedades citadas anteriormente e na importância do uso das plantas medicinais pela população da região nordeste, o presente estudo visa expor os benefícios e potenciais usos das mesmas. Com isso, é possível promover o uso correto e apresentar a relação dessas plantas com os estados da região nordeste e sua real importância para com a promoção da saúde.

\section{Fundamentação Teórica}

Os metabólitos secundários extraídos das plantas são subdivididos em três classes principais: terpenoides, alcalóides e compostos fenólicos, os quais apresentam atividade farmacológica interessante (Pal et al., 2014; Pereira et al., 2016; Savithramma et al., 2011). Além disso, alguns estudos têm demonstrado que esses metabólitos possuem também ações anti-inflamatória, antimicrobiana, cicatrizante e antitumoral (Kowalski et al., 2005; Bankeu et al., 2017; Smiljkovic et al., 2017; Zhao et al., 2017).

Embora muitas plantas tenham seu valor medicinal reconhecido, que está em constante comprovação científica, a cultura popular colabora com o uso indiscriminado de plantas 
medicinais no contexto da automedicação, exigindo o estudo de seus constituintes, o mecanismo de ação terapêutica e a identificação de princípios ativos responsáveis pelas diversas atividades biológicas relatadas pela população (Ford et al., 2014). Nesse sentido, o objetivo deste estudo foi identificar as principais plantas medicinais utilizadas na região Nordeste do Brasil e suas propriedades biológicas cientificamente comprovadas.

\section{Metodologia}

A pesquisa é de natureza qualitativa e foi realizada durante o primeiro semestre de 2019. O campo de pesquisa foi constituído por análises de artigos localizados na plataforma Google Acadêmico, Plataforma PubMed e Scielo, com o objetivo de reunir dados sobre as Plantas Medicinais mais utilizadas na medicina popular da Região Nordeste do Brasil. Além disso, ainda foram consultados dados do Ministério da Saúde do Brasil e das Secretarias de Saúde dos nove estados da região estudada- Alagoas, Bahia, Ceará, Maranhão, Paraíba, Pernambuco, Piaú́, Rio Grande do Norte e Sergipe- com o intuito de enumerar e confirmar a presença e utilização das plantas em cada localidade e seu impacto nas respectivas populações.

Foram realizadas diversas pesquisas nas plataformas acadêmicas para a aquisição de informações, posteriormente foram montadas tabelas para a análise do material coletado. Os critérios de inclusão foram voltados aos artigos publicados nos últimos 10 anos (entre 2009 e 2019), onde foram utilizadas palavras chave como: plantas medicinais, Nordeste do Brasil, etnofarmacologia, fitoterápicos e doenças tratadas por plantas. Artigos publicados fora da margem dos 10 anos escolhidos, além dos que incluíam discussão sobre a utilização das mesmas plantas em outras regiões do país, não foram considerados para a pesquisa.

A região inserida para a análise, possui uma extensão de aproximadamente 1.558 .000 $\mathrm{km}^{2}$ de território e uma população 53.081.950, segundo dados do Instituto Brasileiro de Geografia e Estatística (IBGE) e compreende nove estados, sendo eles: Alagoas, Bahia, Ceará, Maranhão, Paraíba, Pernambuco, Piauí, Rio Grande do Norte e Sergipe. Além disso, ainda é válido ressaltar a grande variedade de vegetações e clima na região analisada no presente estudo, o que reflete na grande diversidade de plantas e características das mesmas. 
Figura 1: Metodologia aplicada durante o processo de seleção dos artigos incluídos no trabalho.

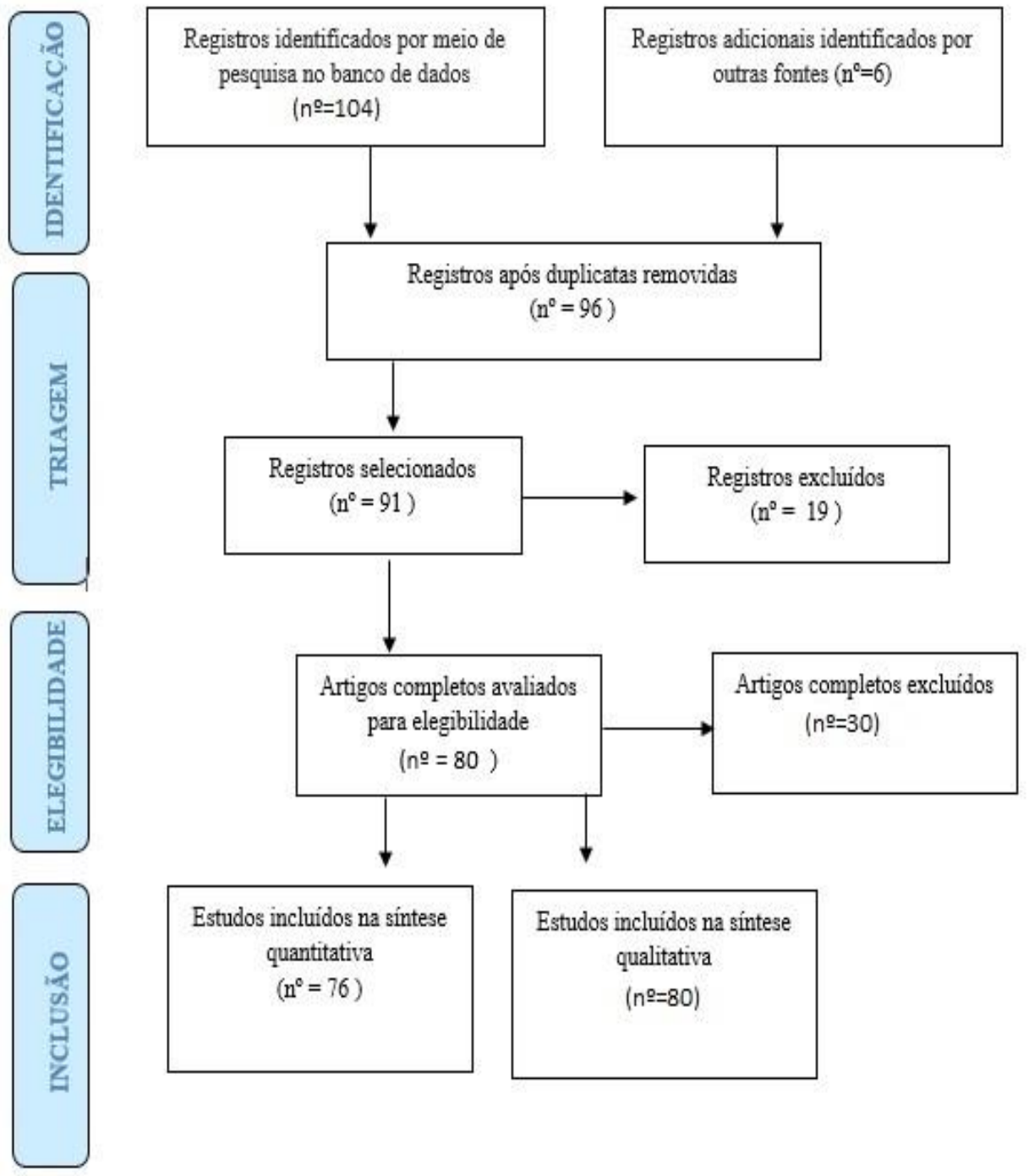

Fonte: Própria

\section{Resultados e discussão}

De acordo com a pesquisa realizada foi possível confirmar as plantas mais utilizadas no tratamento de doenças por comunidades localizadas na Região Nordeste do Brasil (Tabela 1).

Tabela 1: Plantas medicinais utilizadas nos estados da Região Nordeste

\begin{tabular}{|c|c|c|c|c|c|}
\hline $\begin{array}{c}\text { NOME } \\
\text { POPULAR }\end{array}$ & $\begin{array}{c}\text { NOME } \\
\text { CIENTÍFICO }\end{array}$ & $\begin{array}{c}\text { UTILIZAÇÃO } \\
\text { POPULAR }\end{array}$ & FAMÍLIA & $\begin{array}{c}\text { PARTE } \\
\text { UTILIZADA }\end{array}$ & AUTOR \\
\hline Erva cidreira & Lippia alba & $\begin{array}{l}\text { Calmante, cólicas } \\
\text { intestinais, febre. }\end{array}$ & Verbenaceae & Folhas & $\begin{array}{l}\text { Lima, et al } \\
\text { (2016) }\end{array}$ \\
\hline Romã & Punica granatum $L$ & $\begin{array}{l}\text { Gastrite, garganta } \\
\text { inflamada, tosse. }\end{array}$ & Lythraceae & $\begin{array}{l}\text { Semente } \\
\text { e casca }\end{array}$ & $\begin{array}{c}\text { Nascimento } \\
\text {, et. al } \\
\text { (2013) }\end{array}$ \\
\hline
\end{tabular}




$\begin{array}{cc}\text { Jatobá } & \begin{array}{c}\text { Hymenaea courbaril } \\ \text { L. }\end{array} \\ \text { Eucalipto } & \begin{array}{c}\text { Eucalyptus } \\ \text { globulus }\end{array} \\ \text { Capim-Santo } & \begin{array}{c}\text { Cymbopogon } \\ \text { citratus }\end{array} \\ \text { Mastruz } & \begin{array}{c}\text { Chenopodium } \\ \text { ambrosioides L }\end{array} \\ \text { Babosa } & \begin{array}{c}\text { Aloe vera } \\ \text { Arruda }\end{array} \\ \text { Aroeira } & \begin{array}{c}\text { Muta graveolens } \\ \text { urundeuva }\end{array} \\ \text { Alecrim } & \begin{array}{c}\text { Rosmarinus } \\ \text { officinalis L. }\end{array}\end{array}$

Camomila Matricaria recutita

Catuaba Anemopaegma sp

$\begin{array}{cc}\text { Quebra- } & \text { Phyllanthus niruri } \\ \text { pedra } & L\end{array}$

Cumaru

Macaíba

Alfavaca
Tosse, aumenta o sangue, gripe, anemia.

Febre, garganta

inflamada, asma, gripe, congestão nasal.

Dor abdominal e reumática, alteração digestiva, calmante, febre, tosse e dor de cabeça.

Gripe, doenças respiratórias, vasculares, gastrointestinais, endócrinas. Cicatrizante, antibacteriana, antifúngica e antivirótica.

Cólicas e problemas oculares.

Cicatrizante, antiinflamatória, dor de dente.

Calmante, reumatismo, prisão de ventre, bronquite, gripe, coração.

Anti-inflamatória, espasmolítica, sedativa, antibacteriana e antifúngica.

Tônica, estimulante energética,

antioxidante, antiinflamatória e antimicrobiana. Pedras nos rins e pedras na vesícula, alívio da azia, antiviral, diminuição do açúcar no sangue, proteção do fígado.

Cardiotônica, antiespasmódica, antiasmático,antiinflamatória,

Analgésica, bronco dilatadora.

Expectorante, suplemento alimentar.

Adstringente, antioxidante, antimutagênico, antibacteriano, antiinflamatório e antiviral.

Folhas
Fabaceae

Casca

Nascimento

, et. al

Myrtaceae

Folhas, casca e

Oliveira, et. caule al (2015)

Poaceae

Folhas

Santos, et al (2009)

Amaranthaceae

Folhas

Silva, et al (2015)

Bach;

Xanthorrhoeaceae Folhas

Lopes

Rutaceae

Folhas

Barbosa et al (2000)

Anacardiaceae Folhas

Brandão et al (2008)

Folhas, caule e raiz

Wang et al (2008)

Mazokopak is et al (2005)

Bignoniaceae Folhas e flores

Zanolari et al (2005)

Euphorbiaceae

Marques et al (2010)

Fabaceae

Sementes, flores e

Silveira cascas (2003)

Arecaceae

Fruto

Rocha et al. (2008)

Abdeslam

Lamiaceae

Folhas e flores gratissimum $L$

et al., (2007) 


\begin{tabular}{|c|c|c|c|c|c|}
\hline Açafrão & Crocus sp & $\begin{array}{l}\text { Anti-inflamatório, } \\
\text { antioxidante, antiviral, } \\
\text { antibacteriana e } \\
\text { antifúngica. }\end{array}$ & Iridaceae & Raiz & $\begin{array}{l}\text { He et al. } \\
(2015)\end{array}$ \\
\hline Canela & $\begin{array}{c}\text { Cinnamomum } \\
\text { zeylanicum Blume }\end{array}$ & $\begin{array}{c}\text { Antibacteriana, } \\
\text { antiviral, antifúngica e } \\
\text { antioxidante. }\end{array}$ & Lauraceae & Casca & $\begin{array}{c}\text { Guerra et al } \\
\text { (2012) }\end{array}$ \\
\hline Louro & Laurus nobilis L. & $\begin{array}{c}\text { Desobstruente, } \\
\text { estimulante, } \\
\text { expectorante, hepática. }\end{array}$ & Lauraceae & Folhas & $\begin{array}{l}\text { Sellami et } \\
\text { al (2011) }\end{array}$ \\
\hline Boldo & $\begin{array}{l}\text { Peumus boldus } \\
\text { Mol. }\end{array}$ & $\begin{array}{c}\text { Diurética, } \\
\text { antiespasmódica, anti- } \\
\text { séptica, antibacteriana, } \\
\text { anti-inflamatória, } \\
\text { antioxidante, } \\
\text { desintoxicante, } \\
\text { vermífuga. }\end{array}$ & Monimiaceae & Folhas & $\begin{array}{c}\text { Quezada et } \\
\text { al (2004) }\end{array}$ \\
\hline
\end{tabular}

Fonte: Própria

Com a análise das informações do Ministério da Saúde e das Secretarias de Saúde dos estados incluídos na pesquisa, foram destacadas as plantas estudadas e a sua distribuição pela região Nordeste, com isso, foi possível relacionar os estados com as respectivas plantas comumente presentes e mais utilizadas para fins terapêuticos em todos os Estados da Região Nordeste, como é exposto na tabela 2.

Tabela 2: Relação da incidência das Plantas Medicinais nos estados nordestinos.

\begin{tabular}{|c|c|c|}
\hline ESTADO & $\begin{array}{l}N^{\circ} \text { DE PLANTAS } \\
\text { ENCONTRADAS }\end{array}$ & PLANTAS ENCONTRADAS \\
\hline Alagoas & 7 & $\begin{array}{c}\text { Eucalipto, Mastruz, Babosa, Arruda, Aroeira, } \\
\text { Alecrim, Quebra-Pedra. }\end{array}$ \\
\hline Bahia & 7 & $\begin{array}{l}\text { Erva-Cidreira, Capim-Santo, Mastruz, } \\
\text { Aroeira, Quebra-Pedra, Alfavaca, Canela. }\end{array}$ \\
\hline Ceará & 12 & $\begin{array}{l}\text { Erva-Cidreira, Romã, Eucalipto, Capim- } \\
\text { Santo, Mastruz, Babosa, Aroeira, Alecrim, } \\
\text { Quebra-Pedra, Cumaru, Alfavaca, Açafrão. }\end{array}$ \\
\hline Maranhão & 13 & $\begin{array}{c}\text { Erva-Cidreira, Aroeira, Romã, Eucalipto, } \\
\text { Capim-Santo, Mastruz, Babosa, Arruda, } \\
\text { Camomila, Quebra-Pedra, Alfavaca, Canela, } \\
\text { Boldo. }\end{array}$ \\
\hline
\end{tabular}


Piauí

9

Pernambuco

16

Paraíba

9

Rio Grande do Norte

Sergipe

Erva-Cidreira, Romã, Eucalipto, Mastruz, Babosa, Aroeira, Arruda, Quebra-Pedra, Boldo.

Erva-Cidreira, Romã, Jatobá, Capim-Santo, Mastruz, Babosa, Arruda, Aroeira, Alecrim, Camomila, Quebra-Pedra, Macaíba, Alfavaca, Canela, Louro, Boldo.

Erva-Cidreira, Romã, Capim-Santo, Mastruz, Aroeira, Camomila, Quebra-Pedra, Cumaru, Boldo.

Erva-Cidreira, Mastruz, Camomila, Arruda, Aroeira, Eucalipto, Babosa, Arruda, QuebraPedra, Alfavaca, Canela, Louro, Boldo, Romã.

Erva-Cidreira, Romã, Eucalipto, CapimSanto, Babosa, Arruda, Aroeira, Alecrim, Catuaba, Quebra-Pedra, Canela, Louro, Boldo.

Fonte: Própria

Entre as plantas relatadas com uso medicinal na Região Nordeste do Brasil, destacamse as que possuem relatos de utilização em todos os estados estudados. São elas: Aroeira (Myracrodruon urundeuva), Mastruz (Chenopodium ambrosioides L.) e Quebra-pedra (Phyllanthus amarus Schumach.), sendo estas utilizadas popularmente para o tratamento algumas enfermidades como processos inflamatórios, problemas respiratórios, gripe, úlcera, dor no fígado e pedra nos rins respectivamente.

As folhas de Myracrodruon urundeuva (aroeira) são muito utilizados na medicina popular em forma de chá para problemas de natureza inflamatória, além disso, o chá é também muito utilizado para lavagem de feridas, para a cicatrização (Brandão et al., 2008). Há também alguns relatos na literatura, que afirmam o potencial efeito cicatrizante e analgésico da $M$. urundeuva em problemas odontológicos, confirmando os usos da planta para o mesmo fim, nas comunidades (Machado e Oliveira, 2014).

Além disso, Alves et al. (2009) avaliaram in vitro a atividade antimicrobiana, antifúngica e antiaderente da $M$. urundeuva sobre microrganismos do biofilme dental e candidiose oral, como alternativa terapêutica odontológica. Observaram-se também atividade antifúngica do extrato de $M$. urundeuva sobre cepas de Cândida albicans, Cândida [122] 
tropicalis e Cândida krusei. Outros autores também descreveram a ação antifúngica do extrato de aroeira (folhas) sob os fungos Colletotrichum gloeosporioides e Corynespora cassiicola (Naruzawa \& Papa, 2011).

Segundo Machado e colaboradores (2014), um dos efeitos biológicos mais conhecidos sobre a M. urundeuva é o seu efeito antimicrobiano, que pode estar associado com os resultados aferidos na medicina popular, sobre a eficácia na cicatrização de ferimentos. Diversos trabalhos na literatura têm testado o extrato da aroeira na inibição do crescimento bacteriano. Bianco (2004) constatou a capacidade de inibir o crescimento bacteriano do extrato vegetal aquoso e hidroalcoólico das folhas da M. urundeuva.

Alves (2009) testou o extrato hidroalcoólico in vitro da M. urundeuva e observou que esta apresentou atividade bactericida e bacteriostática sobre algumas espécies de bactérias como: S. mutans, S. mitis, S. sobrinus, S. sanguis e L. casei; bem como também a ação antifúngica sobre C. albicans, C. tropicalis e C. krusei.

A Chenopodium ambrosioides $L$ popularmente conhecida na região Nordeste do Brasil como Mastruz, possui diversos estudos voltados para o seu potencial antioxidante, inseticida e em especial, antimicrobiano (Abdel-Aziz et al., 2014; Chu et al., 2011). O que tem sido bastante estudado até o momento, são os achados científicos de ações antiparasitárias, antibacterianas e antioxidantes de óleos essenciais extraídos das folhas do mastruz (Monzote et al., 2014).

Embora os alvos terapêuticos na medicina popular, sejam aplicados para o tratamento de doenças respiratórias, pouco se sabe sobre a ação dos extratos e componentes bioquímicos das folhas da $C$. ambrosioides sobre esses tipos de ação. Esse quadro destaca mais uma vez sobre a necessidade de investigações mais especificas da comunidade científica, focando nos alvos terapêuticos populares, para uma melhor confirmação e conhecimento da medicina alternativa.

A terceira planta mais utilizada no NE do Brasil, é a Phyllanthus amarus Schumach, popularmente conhecida como Quebra-pedra, por ser bastante conhecida na medicina popular pelo chá das folhas dessa espécie, supostamente possuir um potencial de desfragmentação de vesículas ou pedras na vesícula e rins, além de ser bastante utilizada também no tratamento de hiperglicemia e inflamações no fígado (Marques et al., 2010).

Embora os seus efeitos ainda não sejam totalmente comprovados cientificamente, na literatura é possível observar alguns trabalhos como os de Faremi et al. (2008) e Srirama et al. (2011), onde foram testados extratos das folhas de Phyllanthus amarus a fim de confirmar o seu efeito hepatoprotetor, obtendo ambos os grupos, resultados significativos tanto na utilização do extrato da referida espécie, como de espécies da mesma família Euphorbiaceae. 
As espécies menos utilizadas são a None (Morinda citrifolia), Confrei (Symphytum officinale), Vinagreira-roxa (Hibiscus sabdariffa), Pau-ferro (Caesalpinia ferrea Mart), Cumaru (Amburana cearenses), Carambola (Averrhoa carambola L.), Tipi (Petiveria alliacea L.) e Malva-branca (Sida cordifolia L.) sendo essas, algumas que foram citadas apenas em um estado nordestino. Entre as plantas encontradas, as famílias botânicas mais representativas foram Fabaceae, Lamiaceae, e Rubiaceae, e esse resultado é confirmado ao observar um número significativo de indivíduos das espécies que foram selecionadas para a revisão.

Nos artigos avaliados também foi possível observar uma maior utilização das folhas das plantas, para fins terapêuticos, em comparação aos demais órgãos. Segundo Cunha et.al. (2015) essa grande utilização se dá pela facilidade da coleta e disponibilidade das folhas, já que elas ficam expostas e estão presas à planta por mais tempo, durante todo o ano, além de concentrarem a maior parte dos princípios ativos necessários para o uso terapêutico.

Nas publicações selecionadas, foi possível observar que a maioria das pessoas que utilizam plantas como método terapêutico nessas regiões, refletem sobre a importância da informação desses conhecimentos na comunidade, incluindo as práticas terapêuticas tradicionais, bem como o caráter familiar da comercialização dos seus recursos.

De acordo com Rodrigues \& Carvalho (2011), essas regiões abrigam grandes grupos de comunidades indígenas, quilombolas, ribeirinhos, pescadores, pequenos produtores rurais e extrativistas, que possuem e fazem uso de um vasto conhecimento sobre a utilização de plantas na medicina popular. E esse conhecimento tem sido passado de gerado a geração, fazendo parte da cultura e costumes dessas comunidades (Giraldi \& Hanazaki 2010). Entretanto, a população tem o habito de usar indiscriminadamente as plantas em geral, em diversas preparações como chás, infusões, pomadas de macerados e extrações alcóolicas dentro do contexto da automedicação (Giraldi \& Hanazaki 2010).

\section{CONCLUSÃO}

Os estudos dos constituintes dessas plantas, bem como seus mecanismos de ação terapêutica, são de grande importância para correlacionar o uso etnofarmacológico com os achados científicos.

Diante da diversidade e do uso de plantas como terapia de doenças, praticados na região do Nordeste do Brasil nos últimos 10 anos, esse estudo serve de estímulo para futuras e promissoras investigações científicas, que possam ratificar e correlacionar os usos populares, com seus constituintes bioquímicos, além de conferir a eficácia dos mesmos sobre as doençasalvo relatadas pelas comunidades e grupos populares, bem como aferir a segurança biológica 
sobre a potencial toxicidade desses compostos.

\section{Referências}

ABDEL-AZIZ, M.S.; SHAHEEN, M.S.; EL-NEKEETY, A.A.; ABDEL-WAHHAB, M.A. Antioxidant and antibacterial activity of silver nanoparticles biosynthesized using Chenopodium murale leaf extract. King Saud University.Journal of Saudi Chemical Society.

ABUAJAH, C.I.; OGBONNA, A.C.; OSUJI, C.M. Functional components and medicinal properties of food: a review. Journal of Food Science and Technology.v.52, n.5, p.25222529, 2015.

AGRA, M.F; DE FREITAS, P.F; FILHO, J.M.B. Sinopse das plantas conhecidas como medicinais e venenosas no Nordeste do Brasil. Revista Brasileira de Farmacognosia Jan./Mar.2007.

ALMEIDA, C.B.R; FÁTIMA, C.; ALBUQUERQUE, U.P. Uso e conservação de plantas e animais medicinais no Estado de Pernambuco (Nordeste do Brasil): um estudo de caso. Interciencia, vol. 27, núm. 6, junio, 2002, pp. 276-285 Asociación Interciencia Caracas, Venezuela.

ALVES, P.M.; QUEIROZ, L.M.G.; PEREIRA, J.V.; PEREIRA, M.S.V. Atividade antimicrobiana, antiaderente e antifúngica in vitro de plantas medicinais brasileiras sobre microrganismos do biofilme dental e cepas do gênero. Rev. Soc. Bras. Med. Trop. vol.42 no.2 Uberaba Mar./Apr. 2009.

ARANTES, E. M.; CREMON, C.; LUIZ, M.A.C. Alterações dos atributos químicos do solo cultivado no sistema orgânico com plantio direto sob diferentes coberturas vegetais. Revista Agraria. nISSN: 1984-2538. Dourados, v.5, n.15, p.47-54, 2012.

ARAÚJO, C.R.F.; SANTIAGO, F.G.; PEIXOTO, M.I.; OLIVEIRA, J.O.D.; COUTINHO, M.S. Use of medicinal plants with teratogenic and abortive effects by pregnant women in a city in Northeastern Brazil. Rev. Bras. Ginecol. Obstet, v.38, p. 127-131, 2016.

ARNOUS, A.H; SANTOS, A.S; BEINNER, R.P.C. Plantas medicinais de uso caseiroConhecimento popular e interesse por cultivo comunitário. Revista Espaço para a Saúde, Londrina, v.6, n.2, p.1-6, jun. 2005.

AZEVEDO, C.F.; QUIRINO, Z.G.M.; BRUNO, R. L. A. Estudo farmacobotânico de partes aéreas vegetativas de aroeira-vermelha. Rev. bras. plantas medicinais. vol.17 no.1 Botucatu Jan./Mar. 2015.

BANKEU, K.J.J.; DIETAGOUM, M.S.; KUMAR, R.; ALI, M.S.; LENTA, N.B.; YOUSUF, S. Crystal structure and Hirshfeld surface analysis of 3-oxours-12-ene-27a,28-dioic acid (quafrinoicacid). Acta Crystallographica Section. E: Crystallographic Communications, v.73, n. 5, p. 763-766, 2017. 
BAPTISTEL, A.C.; COUTINHO, J.M.C.P.; LINS, E.M.F.N.; MONTEIRO, J.M. Plantas medicinais utilizadas na Comunidade Santo Antônio, Currais, Sul do Piauí: um enfoque etnobotânico. Revista Brasileira de Plantas Medicinais, Bom Jesus-PI, v. 16, n.2, p.406425,2014 .

BARROS, B.R.S. Caracterização estrutural e fitoquímica e investigação das atividades antioxidante, antimicrobiana, citotóxica e imunomoduladora promovidas pelo extrato salino das folhas de Malpighia emarginata d.c. (Aceroleira). Monografia apresentada ao Curso de Licenciatura Plena em Ciências Biológicas/UFRPE.

BATISTA, A.A.M.; OLIVEIRA, C.R.M. Plantas utilizadas como medicinais em uma comunidade do semiárido baiano: Saberes tradicionais e a conservação ambiental. Enciclopédia Biosfera, Centro Científico Conhecer- GO, v.10, n.18, p.74, 2014.

BERG, J. M. T. e LUBERT, J. (2008), Bioquímica. 6.Ed. Rio de Janeiro: Guanabara Koogan, 545p.

BRANDÃO, H. N.; NASCIMENTO, J.A.P.; COUTO, R.D.; DAVID, J. P.; DAVID, J.M. Química e Farmacologia de Quimioterápicos antineoplásicos derivados de plantas. Química Nova, v.33, n.6, p.1359-1369, 2010.

CAMPOS, S.C.; SILVA, C.G.; CAMPANA, P.R.V.; ALMEIDA, V.L. Toxicidade de espécies vegetais. Rev. Bras. Pl. Med., Campinas, v.18, n.1.

CARVALHO, J.S.B.; MARTINS, J.D.L.; MENDONÇA, M.C.S.; LIMA, L.D. Uso popular das plantas medicinais na comunidade da Várzea, Garanhuns-PE. Revista de biologia e ciências da terra, v.13, n. 2, 2013.

CHAVES, E.M.F., BARROS, R.F.M. Diversidade e uso de recursos medicinais do carrasco na APA da Serra da IIbiapaba, Piauí, Nordeste do Brasil. Revista Brasileira de Plantas Medicinais, v.14,n.3, 2012.

CHU, S.S; HU, J.F; LIU, Z.L. Composition of essential oil of Chinese Chenopodium ambrosioides and insecticidal activity against maize weevil, Sitophilus zeamais. Published online inWiley Online Library: 24 February 2011.Ciência agrotécnica, v. 25, p. 102-123, 2011.

CONCEIÇÃO, G. M.; RUGGIERI, A. C.; ARAUJO, M. F. V.; CONCEIÇÃO, T. T. M. M.; CONCEIÇÃO, M. A. M. M. Plantas do cerrado: comercialização, uso e indicação terapêutica fornecida pelos raizeiros e vendedores, Teresina, Piauí. Scientia Plena, v.7, n.12, 2011.

CORREA, N.; SOARES, M.C.F.; BAISCH, A.L.M. Conhecimento do tema plantas medicinais e fitoterápicos como instrumento tecnológico na formação dos acadêmicos de enfermagem. Journal Of Health Sciences, v.30, n.2, 2018.

CUNHA, A. L.; MOURA, K. S; BARBOSA, J. C; SANTOS, A. F. Os metabólitos secundários e sua importância para o organismo. DIVERSITAS JOURNAL. Santana do Ipanema/AL. vol 1, n. 2, p.175-181, mai./ago. 2016.

CUNHA, M.M.C.;GONDIM, R.S.D.; BONFIM, B.F.; JUNIOR, N.J.P.B.; BARROSO, W.A.; 
VILANOVA, C.M. Perfil etnobotânico de plantas medicinais comercializadas em feiras livres de São Luís, Maranhão, Brasil. Scientia Plena, v.11, n.12, 2015.

DA CRUZ, P.R., SOUSA, H.A., COELHO, G.P.B., ARAÚJO, M.F.N., VICTOR,P. Riqueza e importância das plantas medicinais do Rio Grande do Norte. Revista de Biologia e

Ciências da Terra, v.11, n.1,p.157-168, 2011.

DAVID, M.; PASA, M.C.; As plantas medicinais e a etnobotânica em Várzea Grande, MT, Brasil. Interações. Campo Grande, v.16, n.1, p.97-108, jan/jun.,2015.

DE MORAIS, S.M; DANTAS, J.D.P; DA SILVA, A.R.A; MAGALHÃES, E.F. Plantas medicinais usadas pelos índios Tapebas do Ceará. Revista Brasileira de Farmacognosia ,Abr./Jun. 2005.

DE SÁ, C.G; DE BARROS, S.O; GOMES, A. P; SILVA FILHO, F. A; TEIXEIRA, K.S.S. Plantas medicinais usadas na região nordeste: revisão integrativa. Rev. bras. plantas med. vol.16 no.4 Botucatu Oct./Dec. 2014.

FAREMI, T.Y.; SURU, S.M; FAFUNSO, M.A.; OBIOHA, U.E. Hepatoprotective potentials of Phyllanthus amarus against ethanol-induced oxidative stress in rats. www.elsevier.com/ locate/foodchemtox.

FEIJÓ, E.V.R.S.; PEREIRA, A.S.; SOUZA; L.R.; SILVA, L.A.M.; COSTA, L.C.B. Levantamento preliminar sobre plantas medicinais utilizadas no bairro Salobrinho no município de Ilhéus, Bahia. Revista Brasileira de Plantas Medicinais, v.15, n.4, p.595-604, 2013.

FERREIRA, R.O.; CARVALHO, M.G.; SILVA, T.M.S. Ocorrência de Biflavonoides em Clusiaceae: Aspectos Químicos e Farmacológicos. Química Nova, v.35, n.11, p.2271-2277, 2012.

FIRMO, W. C. A. et al. Contexto histórico, uso popular e concepção científica sobre plantas medicinais. Caderno de Pesquisa, v. 18, n. especial, p. 90-95, 2011.

FORD, J.B.; SUTTER, M.E.; OWEN, K.; ALBERTSON, T.E. Volatile Substance Misure: An Updated Review of Toxicity and Treatment. Clin. Reviews in Allergy \& Immunology, v. 46, p. 19-33, 2014.

FRANÇA, E.; VASCONCELLOS, A.G. Patentes de fitoterápicos no Brasil: uma análise do andamento dos pedidos no período de 1995-2017. Cadernos de Ciência \& Tecnologia, Brasília, v. 35, n. 3, p. 329-359, set./dez. 2018.

FREITAS, A.V.L.; COELHO, M.F.B.; PEREIRA, Y.B.; NETO, E.C.F.; AZEVEDO, R.A.B. Diversidade e usos de plantas medicinais nos quintais da comunidade de São João da Varzea, Mossoró-RN. Revista Brasileira de Plantas Medicinais, v. 17, n. 4, Botocatu, 2015.

FREITAS, V.S.;RODRIGUES, R.A.F.; GASPI, F.O.G. Propriedades farmacológicas da Aloe vera (L.) Burm. f. Revista Brasileira de Plantas Medicinais, v.16,n.2, p.299-307, 2014.

GIRALDI, M.; HANAZAKI, N. Uso e conhecimento tradicional de plantas medicinais no 
Sertão do Ribeirão, Florianópolis, SC,Brasil. Acta bot. Bras., v.24, n.2, p.395-406, 2010.

GOMES, T.B.; BANDEIRA, F.P.S.F. Uso e diversidade de plantas medicinais em uma comunidade quilombola no Raso da Catarina, Bahia. Acta bot.Bras., v.26, n.4, p.796-809, 2012.

GUERRA, P. M.; NODARI, O. R.; SIMÕES, M. O. Biodiversidade: aspectos biológicos, geográficos, legais e éticos. In: et al. Farmacognosia: da planta ao medicamento. 3. ed. Porto Alegre: UFRGS; Florianópolis: UFSC, 2001. p.15.

ISHAQ, N.;BILAL,M.; IQBAL,H.M.N. Medicinal Potentialities of Plants Defensins: A Review with Applied Perspectives. Medicines, fev, 2019.

KOWALKI, J.; SAMOJEDNY, A.; PAUL, M.; PIETSZ, G.; WILCZOK, T. 2005. Effect of apigenin, kaempferol and resveratrol on the expression of interleukin-1beta and tumor necrosisfactor-alpha genes in J774.2 macrophages. Rep. Pharmacol. 57(3), 390-394, 2005.

KUMAR, B.M.; NAIR, P.K.R. The enigma of tropical home gardens. Agroforestry systens, vol. 19, p. 195-207, 2004.

LANA, S. L. B. et al. Design de biojoias: desenvolvimento de produtos com perfil sustentável. In: ENCONTRO NACIONAL DA ANPPAS, 5., 2010, Florianópolis. Resumos... Florianópolis: ANPPAS, 2010. p. 1-13.

LEMOS, J.R.; ARAÚJO, J.L. Estudo etnobotânico sobre plantas medicinais na comunidade de Curral Velho, Luís Correia, Piauí, Brasil. Biotemas, UFSC, v.28, n.2, 2015.

LIMA, I.E.O.; NASCIMENTO, L.A.M.; SILVA, M.S. Comercialização de Plantas Medicinais no Município de Arapiraca-AL. Revista Brasileira de Plantas Medicinais, v.18, n.2, p.462-472, 2016.

LINHARES, J.F.P.; HORTEGAL, E.V.; RODRIGUES, M.I.A.; SILVA, P.S.S. Etnobotânica das principais plantas medicinais comercializadas em feiras e mercados de São Luís, Estado do Maranhão,Brasil. Revista Pan-Amazônica de Saúde, v.5, n.3,set, 2014.

LOPES, R.M.; OLIVEIRA, T.D.; NAGEM, T.J.; PINTO, A.D.S. Flavonóides. Biotecnologia Ciência \& Desenvolvimento. 2010;3(14).

MACHADO, A.C.; OLIVEIRA, R.C. Medicamentos Fitoterápicos na odontologia: evidências e perspectivas sobre o uso da aroeirado-sertão (Myracrodruon urundeuva Allemão). Rev. bras. plantas med. vol.16 no.2 Botucatu Apr./June 2014.

MACIEL, M.A.M.; PINTO, A.C.; JUNIOR, V.F.V. Plantas Medicinais: A Necessidade de Estudos Multidisciplinares. Química Nova, v.25, n.3,p.429-438,2002.

MAIA-ALMEIDA, C.I.; MING, L.C.; MARQUES, M.O.M.; MAGALHÃES, P.M.; QUEIROZ, S.C.N.; SCRAMIM, S.; MISCHAN, M.M.; MONTANARI-JR,; PEREIRA, B.;FERREIRA, M.I. Densidade de plantio e idade de colheita de quebra-pedra [Phyllanthus amarus (Schumach. \& Thonning) genótipo Unicamp-CPQBA 14] na produtividade de filantina. Rev. Bras. Pl. Med., Botucatu, v.13, especial, p.633-641, 2011. 
MANETTI, L.M.; TURRA, A.F.; TAKEMURA, O.S.; SVIDZINSKI, T.I.E.; LAVERDE, J.A. Avaliação das atividades antimicrobiana, citotóxica, moluscicida e antioxidante de Bromelia antiacantha Bertol. (Bromeliaceae). Revista Brasileira de Plantas Medicinais, Botucatu, v.12, n.4, p.406-413,2010.

MARINHO, M.G., ANDRADE, L.H.C. Levantamento etnobotânico de plantas medicinais em área de caatinga no município de São José de Espinharas, Paraíba, Brasil. Revista Brasileira de Plantas Medicinais, v.13, n.2, p.170-182, 2011.

MINISTÉRIO DA SAÚDE. Secretaria de Ciência, Tecnologia e Insumos Estratégicos Departamento de Assistência Farmacêutica e Insumos Estratégicos. Política e Programa Nacional de Plantas Medicinais e Fitoterápicos. Brasília - DF 2016.

MONZOTE, L.; PASTOR, J.; SCULL, R.; GILLE, L. (2014). Antileishmanial activity of essential oil from Chenopodium ambrosioides and its main components against experimental cutaneous leishmaniasis in BALB/c mice. Phytomedicine 21(8-9):1048-52.

MORAIS, S.M; LIMA, K.S.B.; SIQUEIRA, S.M.C.; CAVALCANTI, E.S.B. ; SOUZA, M.S.T. ; MENEZES, J.E.S.A.; TREVISAN, M.T.S. Correlação entre as atividades antiradical, antiacetilcolinesterase e teor de fenóis totais de extratos de plantas medicinais de farmácias vivas. Revista Brasileira de Plantas Medicinais, v.15, n.4, p.575-582,2013.

NARUZAWA, E.S.; PAPA, M.F.S. Antifungal activity of extracts from brazilian Cerrado plants on Colletotrichum gloeosporioides and Corynespora cassiicola. Rev. Bras. Pl. Med., Botucatu, v.13, n.4, p.408-412, 2011.

NASCIMENTO, W. M.C.; MELO, O.F.; SILVA, I.F.; SOUZA, F.L. Plantas medicinais e sua utilização pelas comunidades do município de Sobral, Ceará. v.2,n.1, 2013.

NETO, F.R.G.; ALMEIDA, G.S.S.A.; JESUS, N.G.; FONSECA, M.R. Estudo etnobotânico de plantas medicinais utilizadas pela comunidade do Sisal no município de Catu, Bahia, Brasil. Revista Brasileira de Plantas Medicinais, v.16, n.4, p.856-865, 2014.

NOGUEIRA, R.C.; CERQUEIRA, H.F. de; SOARES, M.B.P. Patenting bioactive molecules from biodiversity: the Brazilian experience. Expert Opinion on Therapeutic Patents, v.20, p.1-13, 2010. DOI: 10.1517/13543770903555221.

OLIVEIRA, D.M.S.; LUCENA, E.M.P. O uso de plantas medicinais por moradores de Quixadá-Ceará. Revista Brasileira de Plantas Medicinais, v.17, n.3, p. 407-412, 2015.

OLIVEIRA, D.R.; JÚNIOR, F.E.B.; SAMPAIO, L.A.; TORRES, J.C.; RAMOS, A.G.B.; NUNES, A.A. Ethnopharmacological usage of medicinal plants in genitourinary infections by residentes of Chapada do Araripe, Crato, Ceará, Brazil. Revista Brasileira de Promoção à Saúde, v.25, n.3, 2012.

PAL, A. et. al. (2014). Bioactive Compounds and Properties of Seaweeds - A Review. Open Access Library Journal, 1, pp. 752-769.

PEREIRA, P.S; RUYZ, L.L; DE PAULA, J. Ações terapêuticas do capim-santo: uma revisão 
de literatura. Revista Saúde em Foco - Edição nº 10 - Ano: 2018.

PEREIRA, R. J.; CARDOSO, M.G. Metabólitos secundários vegetais e benefícios antioxidantes. J. Biotec. Biodivers. v. 3, N.4: pp. 146-152, Nov. 2012.

PETROVSKA, B. B. (2012). Historical Review of Medicinal Plants Usage. Pharmacog. Rev., 6 (11), pp. 1-5.

RAMOS, E.S.; DAMASCENA, R.S. Avaliação do uso de plantas medicinais na academia da saúde do município de Rio de Contas/BA. Revista Multidisciplinar e de Psicologia, v.12, n. $42,2018$.

REIS,S.G. Levantamento do uso de Plantas Medicinais por agricultores de municípios de Sergipe. Trabalho de Conclusão de Curso, UFS, 2018.

RIBEIRO, D.A.; MACÊDO, D.G.; OLIVEIRA, L.G.S.; SARAIVA, M.E.; OLIVEIRA, S.F.;SOUZA, M.M.A.; MENEZES, I.R.A. Potencial Terapêutico e uso de plantas medicinais em uma área de Caatinga no estado do Ceará, nordeste do Brasil. Revista Brasileira de Plantas Medicinais, Campinas, v.16, p.912-930, 2014.

ROCHA, F. A. G.; ARAÚJO, L. S. G.; LIMA, T. G. D.; SILVA, E. R.; SILVA, P. A.;GUNDIM, M. K. M.; ARAÚJO, M. F. F.; COSTA,N. D. L. Características do comércio informal de plantas medicinais no município de Lagoa Nova/RN. Holos, v.5, 2013.

ROCHA, L.L.; SOUSA L. S.; CAETANO, T. S. Importância do metabolismo secundário para as plantas. Universidade Federal do Amazonas. Manaus-AM 2018.

RODRIGUES, V.E.G.; CARVALHO, D.A. Levantamento Etnobotânico De Plantas Medicinais Do Domínio Cerrado Na Região Do Alto Rio Grande, Minas Gerais. Rev. Bras. Pl. Med., Botucatu, v.9, n.2, p.17-35, 2007.

ROQUE, A.A.; ROCHA, A.M.; LOIOLA, M.I.B.; Uso e diversidade de plantas medicinais da Caatinga na comunidade rural de Laginhas, município de Caicó, Rio Grande do Norte (nordeste do Brasil). Revista Brasileira de Plantas medicinais, Botucatu-SP, v.12, n.1, p.31$42,2010$.

ROSSATO, M.B.; DENARDIN, M.L.B.; SILVA, F.M.; RESSEL, L.B. Plantas Medicinais: o saber sustentado na prática do cotidiano popular. Revista de Enfermagem, v. 15, n.1, janmar, p.132-139, UFRJ, 2011.

SAMUNI-BLANK, M. et. al. (2012). Intraspecific directed deterrence by the mustard oil bomb in a desert plant. Current Biol., 22 (13), pp. 1218-1220.

SANTOS, E. O.; LIMA, L. S.; DAVID, J. M., MARTINS, L. C.; GUEDES, M. L. S.; DAVID, J.P.; Nat. Prod. Res. 2010. Bioactive Oleanane, Lupane and Ursane Triterpene Acid Derivatives. DO - 10.3390/molecules 171012197. Molecules Journal.

SANTOS, S.L.D.X; ALVES, R.R.N.; SANTOS, S.L.D.X.; BARBOSA, J.A.A.; BRASILEIRO, T.F. Plantas utilizadas como medicinais em uma comunidade rural do semiárido da Paraíba, Nordeste do Brasil. Revista Brasileira de Farmácia, 2011. 
SANTOS-LIMA, T.M.; SANTOS, D.R.V.; SOUZA, R.M.; BASTOS, N.G.; SANTOS, M.A.V.; NUNES, E.S.; LIMA, A.G.D. Plantas Medicinais com Ação Antiparasitária: conhecimento tradicional na etnia Kantaruré, aldeia Baixa das Pedras, Bahia, Brasil. Revista Brasileira de Plantas Medicinais, v.18, n.1, p.240-247, 2016.

SAVITHRAMMA, N. et. al. (2011). Screening of medicinal plants for secondary metabolites. Middle-East J. Sci. Res., 8, pp. 579-584.

SILVA, C.G.; MARINHO, M.G.V.; LUCENA, M.F.A.; COSTA, J.G.M. Levantamento etnobotânico de plantas medicinais em área de Caatinga na comunidade do Sítio Nazaré município de Milagres, Ceará, Brasil. Revista Brasileira de Plantas Medicinais, v.17, n.1, p. 133-142, 2015.

SILVA, N.; LUCENA, R.F.P.; LIMA, J.R.F.; LIMA, G.D.S.; CARVALHO, T.K.N.; JÚNIOR, S.P.S.; ALVES, C.A.B. Conhecimento e uso da vegetação nativa da Caatinga em uma Comunidade Rural da Paraíba, Nordeste do Brasil. Bol. Mus. Biol. Mello Leitão, abr, 2014.

SILVA, N.C.B.; REGIS, A.C.D.; ESQUIBEL, M.A.; SANTOS, J.E.S.; ALMEIDA, M.Z. Uso de Plantas Medicinais na comunidade quilombola da Barra II-Bahia, Brasil. Bol Latinoam Caribe Plant Med Aromat,p.435-453, 2012.

SILVA, T.S.S.; MARISCO, G. Conhecimento etnobotânico dos alunos de uma escola pública no município de Vitória da Conquista/BA sobre plantas medicinais. Biofar, Campina GrandePB, v.9,n.2, p.62-73, jun/ago, 2013.

SIMÕES, C. M. O.; SCHENKEL, E. P.; GOSMAN, G.; MELLO, J. C. P.; MENTZ, L. A.; PETROVICK, P. R. (2007). Farmacognosia: da planta ao medicamento. Florianópolis: Editora da UFSC, 1102p.

SIMPLICIO, F.G.; PEREIRA, M.M. Aspectos Químicos e Farmacológicos de Byrsonima (Malpighiaceae). Química Nova, v.34, n.6,p.1032-1041,2011.

SMILJKOVIC, M.; STANISAVLJEVIC, D.; STOKKOVIC, D.; PETROVIC, I.; VICENTIC, J.M.; GRDADOLNIK, S.G.; MARKOVIC, D.; SANKOVIC-BABICE, S.; GLAMOCLIJA, J.; STEVANOVIC, M.; SOKOVIC, M. Apigenin-7-O-glucoside versus apigenin: Insight into the modes of anticandidal and cytotoxic actions. Excli journal., v, 16, p. 795-807, 2017.

SOBRINHO, O.P.L.; PEREIRA, A.I.S.; CANTANHEDE, E.K.P.; XAVIER, R.S.; OLIVEIRA, L.S.; PEREIRA, A.G.S.; CRUZ, C.H.G. Estudo etnobotânico de plantas medicinais e indicações terapêuticas no povoado Fomento, município de Codó, Maranhão, Brasil. Revista Cubana de Plantas Medicinales,v.23, n. 1, 2018.

SOUZA, M.Z.S.; ANDRADE, L.R.S.; FERNANDES, M.S.M. Levantamento sobre plantas medicinais comercializadas na feira livre da cidade de esperança- PB. Revista de biologia e farmácia, v.5,n.1, 2011.

SRIRAMA, R.; DEEPAK, H. B.; SENTHILKUMAR, U.; RAVIKANTH, G.; GURUMURTHY, B.R.; SHIVANNA, M. B. Hepatoprotective activity of Indian Phyllanthus. 
Pharmaceutical Biology Journal.Volume 50, 2012 - Issue 8.

VIEIRA,L.S.; SOUSA, R.S.; LEMOS, J.R. Plantas Medicinais conhecidas por especialistas locais de uma comunidade rural maranhense. Revista Brasileira de Plantas Medicinais, v.17, n.4, p. 1061-1068, 2015.

YAMAGUCHI, K.K.L.; PEREIRA, C.V.L.; LIMA, E.S.; JUNIOR, V.F.V. Química e Farmacologia do Bacuri (Platonia insignis). Scientia Amazonia, v.3, n.2, p.39-46, 2014.

ZHAO, H.; LIU, Q.; WANG, S.; DAI, F.; CHENG, X.; CHEN, W.; ZHANG, M.; CHEN, D. In vitro additive antitumor effects of Dimethoxycurcumin and 5-fluorouracil in colon câncer cells. Cancer medicine, v. 6, n. 7, p. 1698-1706, 2017. 


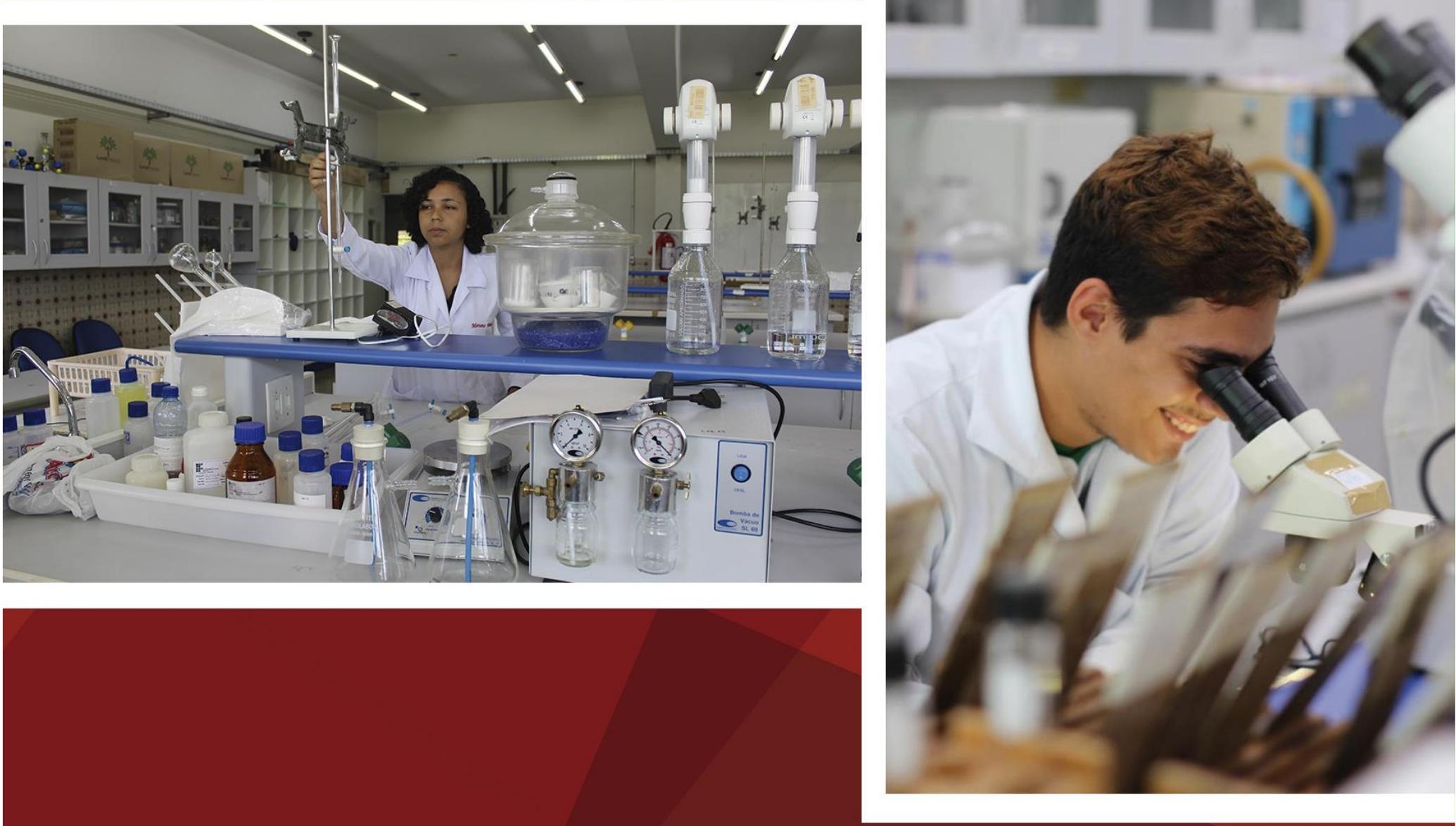

